\title{
Using natural history collections to investigate changes in pangolin (Pholidota: Manidae) geographic ranges through time
}

\author{
Emily Buckingham ${ }^{\text {Equal first author, } 1,2}$, Jake Curry ${ }^{\text {Equal first author, } 2}{ }^{2}$, Charles Emogor ${ }^{3,4}$, Louise Tomsett ${ }^{1}$, Natalie Cooper ${ }^{\text {Corresp. } 1}$ \\ 1 Department of Life Sciences, Natural History Museum, London, London, United Kingdom \\ 2 Department of Life Sciences (Silwood Park), Imperial College London, Ascot, United Kingdom \\ 3 Department of Zoology, University of Cambridge, Cambridge, United Kingdom \\ 4 IUCN SSC Pangolin Specialist Group, Zoological Society of London, London, UK \\ Corresponding Author: Natalie Cooper \\ Email address: natalie.cooper@nhm.ac.uk
}

Pangolins, often considered the world's most trafficked wild mammals, have continued to experience rapid declines across Asia and Africa. All eight species are classed as either Vulnerable, Endangered or Critically Endangered by the International Union for Conservation of Nature (IUCN) Red List. Alongside habitat loss, they are threatened mainly by poaching and/or legal hunting to meet the growing consumer demand for their meat and keratinous scales. Species threat assessments heavily rely on changes in species distributions which are usually expensive and difficult to monitor, especially for rare and cryptic species like pangolins. Furthermore, recent assessments of the threats to pangolins focus on characterising their trade using seizure data which provide limited insights into the true extent of global pangolin declines. As the consequences of habitat modifications and poaching/hunting on species continues to become apparent, it is crucial that we frequently update our understanding of how species distributions change through time to allow effective identification of geographic regions that are in need of urgent conservation actions. Here we show how georeferencing pangolin specimens from natural history collections can reveal how their distributions are changing over time, by comparing overlap between specimen localities and current area of habitat maps derived from IUCN range maps. We found significant correlations in percentage area overlap between species, continent, IUCN Red List status and collection year, but not ecology (terrestrial or arboreal/semi-arboreal). Human population density (widely considered to be an indication of trafficking pressure) and changes in primary forest cover, were weakly correlated with percentage overlap. Our results do not suggest a single mechanism for differences among historical distributions and present-day ranges, but rather show that multiple explanatory factors must be considered when researching pangolin population declines as variations 
among species influence range fluctuations. We also demonstrate how natural history collections can provide temporal information on distributions and discuss the limitations of collecting and using historical data. 
1 Using natural history collections to investigate changes in pangolin (Pholidota: Manidae) geographic ranges through time.

4 Emily Buckingham ${ }^{1,2^{*}}$, Jake Curry ${ }^{2}$, Charles Emogor ${ }^{3,4}$, Louise Tomsett ${ }^{1}$, and Natalie Cooper ${ }^{1}$

6 1Department of Life Sciences, Natural History Museum London, London, UK.

$7 \quad$ 2Department of Life Sciences (Silwood Park), Imperial College London, Ascot, UK.

8 3Department of Zoology, University of Cambridge, Cambridge, UK.

$9 \quad{ }^{4}$ IUCN SSC Pangolin Specialist Group, Zoological Society of London, London, UK

10 *Equal first authors

11

12 Corresponding Author: Natalie Cooper

13

14 Email address: natalie.cooper@nhm.ac.uk

15

16

17

18 


\section{Abstract}

20 Pangolins, often considered the world's most trafficked wild mammals, have continued to

21 experience rapid declines across Asia and Africa. All eight species are classed as either

22 Vulnerable, Endangered or Critically Endangered by the International Union for Conservation of

23 Nature (IUCN) Red List. Alongside habitat loss, they are threatened mainly by poaching and/or

24 legal hunting to meet the growing consumer demand for their meat and keratinous scales.

25 Species threat assessments heavily rely on changes in species distributions which are usually

26 expensive and difficult to monitor, especially for rare and cryptic species like pangolins.

27 Furthermore, recent assessments of the threats to pangolins focus on characterising their trade

28 using seizure data which provide limited insights into the true extent of global pangolin declines.

29 As the consequences of habitat modifications and poaching/hunting on species continues to

30 become apparent, it is crucial that we frequently update our understanding of how species

31 distributions change through time to allow effective identification of geographic regions that are

32 in need of urgent conservation actions. Here we show how georeferencing pangolin specimens

33 from natural history collections can reveal how their distributions are changing over time, by

34 comparing overlap between specimen localities and current area of habitat maps derived from

35 IUCN range maps. We found significant correlations in percentage area overlap between

36 species, continent, IUCN Red List status and collection year, but not ecology (terrestrial or

37 arboreal/semi-arboreal). Human population density (widely considered to be an indication of

38 trafficking pressure) and changes in primary forest cover, were weakly correlated with

39 percentage overlap. Our results do not suggest a single mechanism for differences among

40 historical distributions and present-day ranges, but rather show that multiple explanatory factors

41 must be considered when researching pangolin population declines as variations among

42 species influence range fluctuations. We also demonstrate how natural history collections can

43 provide temporal information on distributions and discuss the limitations of collecting and using

44 historical data. 
45

46 Keywords: Manidae, museum specimens, range contractions, extinction risk

47

48

49

50

51 


\section{Introduction}

53 Pangolins (Pholidota: Manidae) are insectivorous mammals found in parts of Africa and Asia

54 (Hua et al. 2015). They are considered the world's most trafficked wild mammal due to

55 significant consumer demand for their scales and meat (Challender et al. 2015; Cheng et al.

56 2016). Historically, both African and Asian species have locally been traded for consumption,

57 but as local population levels have declined in parts of Asia (Irshad et al. 2015; Schoppe et al.

58 2020; Challender et al. 2020; Wu et al. 2004), researchers have documented a shift in demand

59 from Asia for African pangolins (Challender et al. 2015; Heinrich et al. 2016) which is believed to

60 be the leading cause of declines in African pangolin populations (IUCN 2020). In addition,

61 habitat destruction and slow reproductive rates restrict the rate at which pangolins can recover

62 from overexploitation (Heinrich et al. 2016), and issues with disease control and dietary

63 husbandry limit the success of captive breeding programs (Hua et al. 2015). As all eight species

64 are listed as either Vulnerable, Endangered or Critically Endangered by the International Union

65 for Conservation of Nature (IUCN; IUCN 2020; Heinrich et al. 2016; Cheng et al. 2017), a better

66 understanding of the threats to, and conservation status of, pangolins is therefore paramount for

67 protecting them.

68

69 Despite listing all eight pangolin species under Appendix I of the Convention on International 70 Trade in Endangered Species (CITES) since 2016, pangolin trafficking has often been poorly 71 documented and not effectively monitored, if it is detected at all (Heinrich et al. 2016), so the 72 actual impact of the global illegal trade on pangolin populations and distributions is unknown.

73 Furthermore, the lack of adequate modern-day records of pangolin presence makes it hard to 74 investigate geographic changes and consequently predict their extinction risks. Effective 75 species threat assessment relies heavily on changes in the geographical distribution of the 76 species over time (criterion B, IUCN Red List Categories and Criteria; IUCN, 2012). Thus, 77 understanding how pangolin distributions have changed in the past decades will provide more 
78 insights into their possible population declines and ultimately inform science-based conservation

79 actions.

80

81 One possible solution to understanding the conservation status of pangolins better is to

82 compare their past and current distributions to highlight regions that may have previously been

83 targeted by traffickers, i.e. regions where species ranges have become smaller, without any

84 obvious associated anthropogenic changes. Museum specimen records can provide both the

85 temporal and spatial data needed to analyse distributional trends (Boakes et al. 2010; Pyke and

86 Ehrlich 2010; Lister et al. 2011; McLean et al. 2016, Meineke et al. 2018), without relying on

87 expensive, time consuming, long-term surveys (Newbold 2010; although museum records have

88 other limitations which we highlight in the Discussion). As a result, historical specimen records

89 can be readily used to improve current threat evaluations for pangolins given the paucity of

90 modern data.

91

92 Using pangolin museum specimen records from the Global Biodiversity Information Facility 93 (GBIF; GBIF 2019) and the Natural History Museum, London (NHM), with geographic range maps and habitat classifications by the IUCN SSC Pangolin Specialist Group (IUCN 2020), we produced area of habitat $(\mathrm{AOH})$ maps representing present-day ranges of pangolins and then investigated geographic range contractions in pangolins over the last 150 years by examining overlaps between historical specimen localities and the $\mathrm{AOH}$ present-day ranges. We also investigated the effects of land-use change as a proxy for habitat loss, and human population 99 size changes as a proxy for increased exploitation (Woodroffe 2000). 


\section{Data collection}

103

104 We downloaded locality data for Manidae specimens from GBIF (GBIF 2019;

105 https://doi.org/10.15468/dl.o1t25o), selecting only preserved specimens with taxonomy and

106 locality information without flagged issues. These data came from 42 international museums,

107 excluding the Natural History Museum, London (NHM). We excluded GBIF records from the

$108 \mathrm{NHM}$, and instead added more complete records from NHM, including data that were not

109 previously available on GBIF. We also excluded specimens with uncertain taxonomy, or genus-

110 level records only, and corrected the taxonomy using Mammal Species of the World (Wilson

111 and Reeder 2005). We downloaded geographic range map polygons (created in 2019), habitat

112 classifications and IUCN Red List statuses for each pangolin species from the IUCN Red List

113 website (IUCN 2020). IUCN geographic range maps represent the best available depiction of

114 the historical, present and projected distribution of a taxon, as judged by expert assessors

115 based on their knowledge of the taxon and the available data. Species are classed as extant in

116 an area if the species is known or thought very likely to currently occur in the area, which

117 encompasses localities with current or recent (last 20-30 years) records where suitable habitat

118 at appropriate altitudes remains (IUCN 2020). We also used Challender et al. (2020) to classify

119 each species as primarily terrestrial or arboreal/semi-arboreal based on whether they are

120 ground or tree-dwelling respectively (Table 1).

\section{Georeferencing}

123 For the NHM locality data, all georeferencing was carried out by one of us (EB) using the GBIF

124 Best Practice guidelines (Chapman and Wieczorek 2006). Each location was found in Google

125 Maps, and decimal latitude and longitude coordinates for the midpoint of the locality were 
126

127

128

129

130

131

132

133

134

135

136

137

138

139

140

141

142

143

146

150

151

144 Curry 2019; Figure 1). The point-radius polygon is a circle around the locality with a radius equal 145 to the error extent of the locality.

147 Area of habitat $(\mathrm{AOH})$ maps

148 We used the known habitat preferences, altitudinal limits and 2019 geographic range polygons 149 all sourced from the IUCN Red List website (IUCN 2020) to create AOH maps for each pangolin

recorded. We also recorded an extent (in $\mathrm{m}$ ) from the midpoint to the furthest place that could still be considered to be within the locality as a measure of error (i.e. the point-radius method; Wieczorek et al. 2004), along with a certainty score $(0,25,50,75$ or $100 \%)$ describing how confident we were that the locality truly fell within the recorded extent. For the GBIF data we followed the same protocol, except where localities had already been georeferenced we used the existing coordinates and just estimated the extent (in $\mathrm{m}$ ).

Before analyses we checked all records for data quality. We excluded specimens with extents $>1000 \mathrm{~km}$ and specimens from zoos or where we suspected the locality data were the shipping, rather than collection, location. Specimens with localities more than $100 \mathrm{~km}$ outside their current geographic range were also checked. Where this was a clear-cut taxonomic error we corrected the taxonomy, for example any Manis species found in Sri Lanka must be Manis crassicaudata as no other members of the genus are found there. If there was no obvious taxonomic error we assumed this was a recording error and omitted the specimen from further analyses. Details of excluded and modified specimens are shown in Tables S1 and S2.

To incorporate georeferencing error, for each specimen locality we created a point-radius polygon from the error extent for that locality, using the R packages sf and sfe (Pebesma 2018; species. Trends in species $\mathrm{AOH}$ over time can be useful in obtaining estimates of their population decline under the IUCN Red List criteria and in assessing levels of fragmentations of 
152 pangolin habitats (IUCN, 2012; Brooks et al. 2019). No elevation data could be found for

153 Phataginus tricuspis and $P$. tetradactyla so just the habitat preferences were used to create the

$154 \mathrm{AOH}$ maps for both of these species. Minimum altitudinal limits were not present for either

155 Smutsia species, so the value was assumed to be 0 (as is the case with all other species where 156 this data was available; Brooks et al 2019). We downloaded a 2018 land cover classification

157 raster (i.e. gridded data) at $100 \mathrm{~m}$ horizontal resolution from the Copernicus Climate Change

158 Service version 2.1.1 (Buchhorn et al. 2019) and an elevation raster from WorldClim (Fick and

159 Hijmans 2017) at $1 \mathrm{~km}$ resolution. Following the methods outlined by Brookes et al. (2019), we

160 used the raster package in $\mathrm{R}$ (Hijmans 2018) to crop both the elevation and land-use rasters for

161 each species using the IUCN range maps to define the extents. We then used the raster

162 calculator in QGIS version 3.14 (QGIS.org, 2020) to create binary rasters using the known

163 habitat preferences and altitude limits of each species, with the following formula (where XX is a 164 species):

$$
\begin{aligned}
& (\text { (XX_elevation" < } 0) \text { * } 0+\left(\left(“ X X \_ \text {elevation" }>=0\right)\right. \\
& \text { AND ("XX_elevation" < = 2015)) * } 1+\left(“ X X \_\right. \text {elevation" > 2015) *0 }
\end{aligned}
$$

167 A value of 1 in the binary raster is therefore suitable habitat and 0 is unsuitable. These binary elevation and land-use rasters were then resampled and multiplied together for each species in $\mathrm{R}$ to create the binary suitable/unsuitable $\mathrm{AOH}$ maps.

\section{Anthropogenic data}

172 Geographical analyses are often based on summarising data within grid cells of a defined size, 173 then using values for each grid cell as input data for downstream analysis (e.g. Derrick et al 174 2020). We downloaded historical and current human population size data as population count 175 and population density from the History Database of the Global Environment (HYDE v3.2.1;

176 Goldewijk et al. 2017) at 5' or 0.083 degree resolution. For land-use change, we downloaded 177 historical land-use states data at $0.25 \times 0.25$ degree spatial resolution from the Land-Use 
178 Harmonization (LUH2) project (LUH2 v2h; http://luh.umd.edu/data.shtml; Hurtt et al. 2020).

179 These data represent the fraction of each $0.25 \times 0.25$ degree grid cell covered by each land-use

180 type. The land-use types we focussed on were forested primary land (primf; all forested areas

181 including scrublands and savanna, previously undisturbed by any human activities post 850),

182 non-forested primary land (primn; all non-forested areas including grasslands and wetlands,

183 previously undisturbed by any human activities post 850) and urban land (urban). Both HYDE

184 and LUH2 data were based on the high data-driven land-use reconstructions from HYDE

185 (Goldewijk et al. 2017).

186

187 For the human population size and the land-use data, we calculated the change in population

188 size or land-use cover (but not both) for each $0.25 \times 0.25$ degree grid cell between 2015

189 (present-day) and 1850, 1900 or 1950 in turn. We used 2015 as our present-day baseline as

190 these were the most recent data available (Goldewijk et al. 2017; Hurtt et al. 2020), and used

1911850 as our earliest historical date as most specimens were collected between 1850 and 1950

192 (ideally we would extract values for the year each specimen was collected, but we do not have

193 year data for all specimens). For each specimen and time period, we then extracted the mean

194 change in every population size or land-use variable across the $0.25 \times 0.25$ degree grid cells

195 occupied by the specimen's point radius polygon. We used these values in our analyses below.

196 Note that specimen MVZ_MVZ:Mamm:125554 was excluded from these analyses because it

197 comes from an extremely small island on the P'eng-hu peninsula and there were not sufficient

198 land-use or human population data within this locality for overlaps to be calculated.

199

200 All data required to repeat the analyses are available on the NHM Data Portal (data.nhm.ac.uk;

201 Buckingham et al. 2019).

202 


\section{Analyses}

204 We used R version 3.6.2 (R Core Team 2019) for all analyses, and the R packages sf

205 (Pebesma 2018), raster (Hijmans 2018), rgdal (Bivand et al. 2018) and sfe (Curry 2019) for all

206 spatial analyses. R code to repeat all the analyses is available on GitHub

207 (github.com/nhcooper123/protecting-pangolins; Cooper et al. 2020).

208

209 To reduce the likelihood of our results being due to error in georeferencing we only included

210 specimens with certainty scores $\geq 50 \%$ and extents $<50 \mathrm{~km}$ in our analyses. Additionally,

211 because we are interested in understanding which localities overlap with current day ranges,

212 rather than specimens per se, we excluded 107 duplicate records, i.e. where multiple

213 specimens of one species were collected from the same locality, in all analyses except those

214 involving collection years. For collection years analyses we instead omitted 84 duplicates where

215 multiple specimens of one species were collected from the same locality in the same year.

216

217 Correlates of overlaps with $\mathrm{AOH}$ maps

218 For each species of pangolin we calculated overlaps between specimen localities and present219 day AOH polygons in two ways (Figure 1). (1) Percentage locality overlap: the percentage of 220 specimen localities (including their error extents) that fall within their species AOH polygons; (2)

221 Percentage area overlap: the mean percentage area of specimen point-radius polygons that 222 overlap with $\mathrm{AOH}$ range polygons. We calculated these percentages for specimens with 223 certainty scores $\geq 50 \%$ and extents $<50 \mathrm{~km}$ with and without duplicates, and for all specimens 224 with certainty scores $>0 \%$, with and without duplicates. We also grouped species by continent, 225 ecology and IUCN Red List status and calculated the percentage overlaps for these groupings. 226 Note that Smutsia temminckii had an extremely complex AOH map because of its broad range, 227 meaning that we were unable to extract overlaps from it due to computational issues (lack of 
228 available memory). We therefore used the IUCN map for this species to estimate overlaps 229 rather than its $\mathrm{AOH}$.

230

231 To test for correlates of overlaps among specimen localities and present-day range maps, we 232 first fitted binomial generalised linear models (GLMs), with the number of specimens whose 233 localities (including their error extents) were within their species AOH polygons (success) and 234 the number of specimens whose localities were not within their species AOH polygons (failure) 235 for each species as the response variable (i.e. a binomial response where the number of 236 successes and failures were jointly modelled). We used the collection year, continent, whether 237 the species was primarily terrestrial or arboreal/semi-arboreal, and IUCN Red List status, as 238 predictors, and used standard model checks for GLMs (Q-Q plot, histogram of residuals, residuals vs. linear predictors, response vs. fitted values) to assess model fit. These analyses have very low power; most have only eight data points, one for each species, except the collection years analysis which has 106 data points, one for each year x species combination.

243 Next, we repeated these analyses using percentage area overlap for each specimen as the response variable. We used the species, collection year, continent, whether the species was primarily terrestrial or arboreal/semi-arboreal and IUCN Red List status, as predictors (note that we could not fit multiple regressions because these resulted in rank deficient matrices because species can be written as a combination of the other predictors). Because percentage area overlap is a proportion, we fitted beta regression models after first transforming percentage area overlap to remove 0 s and 1 s using the following equation (Douma and Weedon 2019):

$$
x_{i}^{t}=x_{i}(n-1)+0.5 / n
$$


253 where $x_{i}^{t}$ is the transformed value of $x_{i}$, and $n$ is the total number of observations in the dataset.

254 We then fitted our models using the betareg function in the betareg $\mathrm{R}$ package (Cribari-Neto 255 and Zeileis 2010) using a logit link function and with both fixed and variable precision $(\phi)$.

256 Estimators from beta regression can be biased, particularly at low sample sizes (Douma and 257 Weedon, 2019, Grün et al. 2012), so we repeated our models using the bias correction and bias 258 reduction methods built into betareg (Grün et al. 2012). We compared these results to our 259 original models to ensure that bias was not influencing our conclusions.

260

261

262

263

264

265

266

267

268

269

270

\section{Results \\ Results}

272

273

274

275

\section{Anthropogenic drivers of range change or contraction}

If species have changed their ranges in response to anthropogenic changes in their habitats, we expect to see negative correlations between measures of overlap in past and present-day ranges and changes in anthropogenic variables. To test this, we used beta regression as described above to determine whether percentage area overlap was correlated with changes in human population size or land-use, between 2015 and 1850, 1900, or 1950 in turn. For human population size we used changes in log population count and log population density as predictor variables. For land-use change we investigated changes in the percentage cover of forested primary land, non-forested primary land and urban land as predictor variables.

Georeferencing

We georeferenced a total of 676 pangolin specimens, including 437 specimens not currently georeferenced on GBIF (Figures 2 and 3). 269 of these had certainty scores $\geq 50 \%$ and extents 
$276<50 \mathrm{~km}$. Of these 269, 162 represented unique collection localities and were used in our

277 analyses (Table 1).

278

279 Correlates of overlaps with $\mathrm{AOH}$ maps

280 Percentage locality overlaps and mean percentage area overlaps for each species, continent, 281 ecological group and IUCN Red List status, for various subdivisions of the data, are shown in 282 Table S3.

283

284 When modelling the number of localities overlapping with species $\mathrm{AOH}$ and those that did not 285 overlap as a binomial response, we found a significant correlation with ecology (binomial GLM: $286 \chi^{2}=4.224, d f=1,6, p=0.040$ ), but not continent (binomial GLM: $\chi^{2}=2.650, d f=1,6, p=$ 287 0.104), IUCN Red List status (binomial GLM: $\chi^{2}=0.532, \mathrm{df}=2,5, p=0.766$ ), or collection year 288 (binomial GLM: $\chi^{2}=1.680, \mathrm{df}=1,104, \mathrm{p}=0.195 ;$ Figure S1). Percentage area overlap was 289 significantly correlated with species, continent, IUCN Red List status and collection year, but not ecology (Table S4, Figure 4). Across species, the four Manis species had lower overlaps than the two Phataginus species, and the two Smutsia species (Figure 4a). Overlaps were higher in more recent years (Figure 4b), and higher in Africa than Asia (Figure 4c), and in Vulnerable and

293 Endangered species compared to Critically Endangered species (Figure 4e).

294

Anthropogenic drivers of range change or contraction

296 There were significant negative correlations between percentage area overlaps and changes in 297 all of the human population size variables (Figure 5; Table S5), i.e. as population size 298 increased, overlaps scores decreased. The pseudo- $R^{2}$ for these relationships, however, were 299 very low (pseudo- $R^{2}$ ranged from 0.021 and 0.032 ) so the observed relationships between 
300 population size and degree of overlap should not be overinterpreted. Percentage area overlap

301 was also significantly correlated with changes in the percentage cover of forested primary land

302 between 1900 and the present, and 1950 and the present, but with no other land-use change

303 variables (Figure 6; Table S5). Specimens found in areas with large decreases in forested

304 primary land tended to have lower overlap scores than those where forest cover had changed

305 less. However, the pseudo- $R^{2}$ values for these models were also very low $(0.052$ and 0.033

306 respectively).

307

308 Discussion

309 Our results show that overlaps between historical localities and present-day ranges of pangolins

310 vary across species, time, continents and extinction risk. These results are mostly driven by

311 differences among species, with the most threatened species belonging to the genus Manis.

312 Occurring in Asia, these species have the lowest percentage overlaps between their historical

313 collection localities and present-day ranges, reflecting both suspected and estimated declines in

314 their populations (Irshad et al. 2015; Schoppe et al. 2020; Challender et al. 2020; Wu et al.

315 2004). Interestingly, species in the African genus Smutsia had the second lowest overlap

316 scores, despite only being classified as Vulnerable by the IUCN Red List (S. gigantea is now

317 listed as Endangered; IUCN 2020). S. gigantea and S. temminckii are large, ground dwelling

318 and prefer relatively open landscapes so may be more accessible and attractive to poachers

319 than smaller arboreal or semi-arboreal pangolins. In addition, the increasing pressure on African

320 pangolin populations to meet Asian consumer demand (Challender et al. 2015; Heinrich et al.

321 2016; Shepherd et al. 2017; Ingram et al. 2018), which is in part due to population declines of

322 their Asian relatives, may also be putting these larger pangolin species at a higher risk of

323 poaching.

324

Peer) reviewing PDF | (2020:06:50159:2:0:NEW 4 Jan 2021) 
325 Correlations between overlaps and human population density - a proxy for overexploitation of 326 species (Woodroffe 2000) - had very low explanatory power. Likewise, although land-use 327 change leading to habitat destruction further increases the vulnerability of pangolins, particularly 328 in South East Asia which has experienced more deforestation than any other tropical region in 329 the world (Zhao et al. 2006), we also did not find strong correlations between land-use change 330 and overlaps. Instead, mechanisms of pangolin range loss are likely more complex. One root of 331 this weak correlation appears to be that even in areas experiencing increases in human 332 population size and urban land cover and decreases in primary forested and non-forested land 333 cover (see Figures 5 and 6), many specimen localities still overlap 100\% with the present-day $334 \mathrm{AOH}$ range. This may be related to how we georeference locality data. Georeferencing is easier 335 and more accurate for named places, often towns and cities, compared to more remote areas, meaning that these sorts of localities are over-represented in our data (Buckingham et al. 2019).

337 This is exacerbated by the georeferencing protocol (see Chapman and Wieczorek 2006) stating 338 that localities with very small extents should have low certainty scores because of the low 339 likelihood that the specimen was actually collected there. This meant many rural localities like 340 farms were dropped from our analyses because their certainty scores were $<50 \%$. Likewise, 341 many wilderness areas, for example localities in national parks, are hard to georeference 342 accurately leading to these localities being dropped from our analyses for having extents > $34350 \mathrm{~km}$. Taken together, this suggests we are more likely to have specimens from urban localities 344 than from natural landscapes. Another notable problem with our data is that we can only record 345 the presence of the species (Tingley and Beissinger 2009) but neither the historical localities nor 346 present-day range maps give any indication of species abundance or population health. A final 347 possibility is that pangolins in many regions are able to adapt to modified habitats, for example, 348 oil palm plantations, urban parks and gardens and rubber plantations (Challender et al. 2020), 349 so maintain their range after human disturbance. It is unlikely, however, that such suboptimal 
350 habitat supports the same population densities as pristine forest. Thus $100 \%$ overlap for a 351 species might actually not be such a positive thing as it first appears.

352

353 Although we assume lack of overlap among historical and present-day ranges indicates range 354 changes or contractions, it may also be the result of error. There may be errors in

355 georeferencing or collection notes, despite our best efforts to mitigate these. Our quality control 356 procedures are designed to deal with uncertainty in georeferencing, but for historical data we 357 cannot be completely sure that the correct place name was recorded (Tingley and Beissinger 358 2009), and often the recorded name is the location of shipping or distribution, rather than the 359 actual collection locality. Locality descriptions on specimen labels are often vague, cryptic or 360 faded so even if the correct place was recorded, it may not be possible to recover that 361 information. We attempted to deal with some of this in our analyses, but it is an issue that future 362 studies should be aware of.

363

364 Error may also be present in the $\mathrm{AOH}$ maps which are dependent on the accuracies of the 365 IUCN range maps, reported habitat preferences and elevational limits of each species (Brooks 366 et al. 2019). The land-use data used to create the AOH maps was created in 2018 and with 367 rapid urbanisation and deforestation in many areas, particularly around South East Asia (Zhao 368 et al. 2006), we suspect there are regions where land-use has changed since these maps were produced. Although $\mathrm{AOH}$ maps cannot be used to compare with either the Extent of Occurrence (EOO) or Area of Occupancy (AOO) thresholds, they provide more detail than the IUCN range

371 maps which is useful when targeting field surveys and assessing habitat fragmentation over 372 time (Brooks et al. 2019). In addition to being easy and cheap to produce with basic statistical 373 software, a time-series of $\mathrm{AOH}$ maps can also be used to derive estimates of species population 374 decline under Red List criterion A (Buchanan et al 2008; Tracewski et al 2016). 
376 Museum specimens, some of which are 150 years old, are only one source of data on historical

377 pangolin distributions. A primary challenge for pangolin conservationists is finding efficient ways

378 to collect, collate and share data on the status of, and threats to, present-day pangolin

379 populations. While $\mathrm{AOH}$ maps and other broad mapping tools (such as extent of occurrence,

380 area of occupancy and species distribution modelling) can help overcome this challenge, it is

381 crucial to consider other data sources such as direct or indirect field observations and sightings

382 by community scientists. These may provide more fine-scale information on distribution patterns

383 and provide a better understanding of how pangolin populations are changing over shorter

384 temporal scales. However, determining how to best share these data to ensure they reach

385 conservationists but not those seeking to exploit the species is an important concern that

386 requires careful consideration. Other data sources, such as eDNA, and stable isotopes or

387 molecular data from seized scales, will also be of key importance moving forwards. Physical

388 specimens will remain critical to future conservation studies, as specimens provide far more

389 information than a sighting, for example the age, sex, health and condition of the animals, which

390 are all important considerations for maintaining healthy populations. Additionally, the potential

391 applications of specimen data are continually expanding, especially with modern research

392 techniques. Museum collections are vital for multidisciplinary research and collaborations and

393 have the potential to unlock previously hidden data contained within specimens using both

394 present-day methods and currently unrealized future research techniques (McLean et al. 2016;

395 Meineke et al. 2018).

396

397

398 Our study highlights the potential and limitations of using museum data to infer range changes

399 and contractions in threatened species which can be used to evaluate present-day extinction

400 risks when modern data is scarce. We georeferenced a total of 676 pangolin specimens,

401 including 437 specimens not currently georeferenced on GBIF. This data is valuable to 
402 conservationists but needs to be used with care. Our results suggest that although it is not 403 possible to accurately estimate geographic ranges from historical locality data alone, museum 404 collections contain a wealth of spatial and temporal information that can be combined to analyse 405 distributional trends. The most valuable data are the older records, i.e. those collected before 406 1900, which are not available from other sources. Future research into pangolin population 407 trends should combine field data, data from museum collections, seizure records and local 408 knowledge to create a full picture of declines in these species.

409

410 Acknowledgements

411 We thank Jeffrey Streicher for input to the ideas that led to this project, and three anonymous 412 reviewers for their helpful comments.

413

\section{References}

415

416

Aisher A., 2016. Scarcity, alterity and value: decline of the pangolin, the world's most trafficked

417 mammal. Conserv. Soc. 14: 317-329.

418

419 Bivand R., Keitt T., Rowlingson B., 2018. rgdal: Bindings for the 'geospatial' data 420 abstraction library. $R$ package version 1.3-6.

421

422 Boakes E.H., McGowan P.J.K., Fuller R.A., Chang-qing D., Clark N.E., O’Connor K., Mace

423 G.M., 2010. Distorted views of biodiversity: spatial and temporal bias in species occurrence 424 data. PLOS Biol. 8: e1000385.

425 
426 Brooks T.M., Pimm S.L., Akçakaya H.R., Buchanan G.M., Butchart S.H.M., Foden W., Hilton-

427 Taylor C., Hoffmann, M., Jenkins C.N., Joppa L., Li B.V., Menon V., Ocampo-Peñuela N.,

428 Rondinini C., 2019. Measuring terrestrial Area of Habitat (AOH) and its utility for the IUCN Red 429 List. Trends Ecol. Evol. 34: 977-986.

430

431 Buchhorn M., Smets B., Bertels L., Lesiv M., Tsendbazar N., Herold M., Fritz F., 2019.

432 Copernicus Global Land Service: Land Cover 100m: collection 2: epoch 2015: Globe (Version 433 V2.0.2) [Data set]. Zenodo. http://doi.org/10.5281/zenodo.3243509

434

435 Buckingham E., Curry J., Emogor C., Tomsett L., Cooper N., 2019. Dataset: Pangolin 436 georeferencing. Natural History Museum Data Portal (data.nhm.ac.uk).

437 https://doi.org/10.5519/0058821.

438

439 Challender D.W., Harrop S.R., MacMillan D.C., 2015. Understanding markets to conserve trade440 threatened species in CITES. Biol. Conserv. 187: 249-259.

441

442 Challender D.W.S., Nash H.C. Waterman C. (eds), 2020. Pangolins: Science, Society and 443 Conservation. Academic Press: London.

444

445 Chapman A.D. \& Wieczorek J. (Eds.). 2006. Guide to Best Practices for Georeferencing, Global 446 Biodiversity Information Facility, Copenhagen.

447

448 Cheng W., Xing S., Bonebrake T.C., 2016. Recent pangolin seizures in China reveal priority 449 areas for intervention. Conserv. Lett. 10: 757-764.

450

451 Chin S.Y., Pantel S., (Eds.). 2009. Pangolin capture and trade in Malaysia. Workshop on trade 
452 and conservation of pangolins native to South and Southeast Asia, TRAFFIC Southeast Asia,

453 Petaling Jaya, Selangor, Malaysia.

454

455 Cooper N., Curry J., Buckingham E., 2020. Protecting-pangolins. Github,

456 github.com/nhcooper123/protecting-pangolins. Code for the paper. Zenodo DOI:

457 10.5281/zenodo.4266580.

458

459 Cribari-Neto F., Zeileis A., 2010. Beta regression in R. J. Statist. Software 34: 1-24.

460

461 Curry J., 2019. sfe (Version v1.0). Zenodo. http://doi.org/10.5281/zenodo.3578490.

462

463 Derrick D.H., Cheok J., Dulvy N.K., 2020. Spatially congruent sites of importance for global

464 shark and ray biodiversity. PLOS ONE 15(7): e0235559.

465 https://doi.org/10.1371/journal.pone.0235559

466

467 Douma J.C., Weedon J.T., 2019. Analysing continuous proportions in ecology and evolution: A 468 practical introduction to beta and Dirichlet regression. Methods Ecol. Evol. 10: 1412-1430.

469

470 Fick S.E., Hijmans R.J., 2017. WorldClim 2: new 1km spatial resolution climate surfaces for

471 global land areas. Int. J. Climatol 37: 4302-4315.

472

473 GBIF. 2019. GBIF.org (08 August 2019) GBIF Occurrence Download. Available from

474 https://doi.org/10.15468/dl.o1t25o [8 August 2019].

475

476 Goldewijk K., Beusen A., Doelman J., Stehfest, E., 2017. Anthropogenic land-use estimates for 477 the Holocene; HYDE 3.2. Earth Syst. Sci. Data. 9: 927-953. 
478

479 Grün B., Kosmidis I., Zeileis A., 2012. Extended beta regression in R: shaken, stirred, mixed, 480 and partitioned. J. Statist. Software. 48: 1-25.

481

482 Heinrich S., Wittmann T.A., Prowse T.A., Ross J.V., Delean S., Shepherd C.R., Cassey P., 483 2016. Where did all the pangolins go? International CITES trade in pangolin species. Glob.

484 Ecol. Conserv. 8: 241-253.

485

486

Hijmans R.J., 2018. raster: Geographic data analysis and modelling. R package version 2.8-4.

487

488

Hua L., Gong S., Wang F., Li W., Ge Y., Li X., Hou F., 2015. Captive breeding of pangolins:

489 current status, problems and future prospects. ZooKeys. 507: 99-114.

490

491 Hurtt, G. C., L. Chini, R. Sahajpal, S. Frolking, B. L. Bodirsky, K. Calvin, J. C. Doelman, J. Fisk, 492 S. Fujimori, K. K. Goldewijk, T. Hasegawa, P. Havlik, A. Heinimann, F. Humpenöder, J. 493 Jungclaus, Jed Kaplan, J. Kennedy, T. Kristzin, D. Lawrence, P. Lawrence, L. Ma, O. Mertz, J. 494 Pongratz, A. Popp, B. Poulter, K. Riahi, E. Shevliakova, E. Stehfest, P. Thornton, F. N. Tubiello, 495 D. P. van Vuuren, X. Zhang (2020). Harmonization of Global Land-Use Change and 496 Management for the Period 850-2100 (LUH2) for CMIP6. Geosci. Model Devel. Disc. 497 https://doi.org/10.5194/gmd-2019-360.

498

499 Ingram D.J., Coad L., Abernethy K.A., Maisels F., Stokes E.J., Bobo K.S., Breuer T., Gandiwa 500 E., Ghiurghi A., Greengrass E., Holmern T., 2018. Assessing Africa-wide pangolin exploitation 501 by scaling local data. Conservation Letters, 11: 241-253.

502 
503 IUCN 2020. The IUCN Red List of Threatened Species. Version 2019-2. Available from

504 http://www.iucnredlist.org [6 January 2020].

505

506 Lister A.M., Climate Change Research Group., 2011, Natural history collections as sources of 507 long-term datasets. Trends Ecol. Evol. 26: 153-154.

508

509 McLean B.S., Bell K., Dunnam J.L., Abrahamson B., Colella J.P., Deardorff E.R., Weber J., 510 Jones A., Salazar-Miralles F., Cook J.A., 2016. Natural history collections-based research:

511 progress, promise, and best practices. J Mammal. 97: 287-297.

512

513 Meineke E.K., Davies T.J., Daru B.H., Davis C.C., 2018. Biological collections for

514 understanding biodiversity in the Anthropocene. Phil. Trans. Roy. Soc. B. 374: 20170386.

515

516 Newbold T., 2010. Applications and limitations of museum data for conservation and ecology, 517 with particular attention to species distribution models. Prog. Phys. Geogr. 34: 3-22.

518

519 Pebesma E., 2018. Simple Features for R: standardized support for spatial vector data. R 520 Journal. 10: 439-446.

521

522 Pyke G.H., Ehrlich P.R., 2010. Biological collections and ecological/ environmental research: a 523 review, some observations and a look to the future. Biol. Rev. 85: 247-266.

524

525 QGIS.org., 2020. QGIS Geographic Information System. Open Source Geospatial Foundation 526 Project. http://www.qgis.org.

527 
528 R Core Team., 2019. R: a language and environment for statistical computing. Version 3.6.1., R 529 Foundation for Statistical Computing, Vienna, Austria. https://www.Rproject.org.

530

531 Shepherd C.R., Connelly E., Hywood L., Cassey P., 2017. Taking a stand against illegal wildlife 532 trade: the Zimbabwean approach to pangolin conservation. Oryx. 51: 280-285.

533

534 Tingley M.W., Beissinger S.R., 2009. Detecting range shifts from historical species occurrences: 535 new perspectives on old data. Trends Ecol. Evol. 24: 625-633.

536

537 Wieczorek, J., Guo, Q., Hijmans, R., 2004. The point-radius method for georeferencing locality

538 descriptions and calculating associated uncertainty. Intl. J. Geogr. Info. Sci. 18: 745-767.

539

540 Wilson D.E., Reeder D.M., 2005. Mammal species of the world: a taxonomic and geographic 541 reference, 3rd Edition, John Hopkins University Press, Baltimore.

542

543 Woodroffe R., 2000. Predators and people: using human densities to interpret declines of large 544 carnivores. An. Conserv. Forum 3: 165-173.

545

546 Zhao S., Peng C., Jiang H., Tian D., Lei X., Zhou X., 2006. Land use change in Asia and 547 the ecological consequences. Ecol. Res. 21: 890-896. 


\section{Table $\mathbf{1}$ (on next page) \\ Details of pangolin dataset}

Table shows the number of specimens used in the analyses where certainty scores $\geq 50 \%$ and extent $<50 \mathrm{~km}$. Numbers in brackets reflect unique collection localities. 


\begin{tabular}{|c|c|c|c|c|c|}
\hline Species & Continent & $\begin{array}{l}\text { IUCN Red } \\
\text { List status }\end{array}$ & Ecology & $\begin{array}{l}\text { Number of } \\
\text { specimens }\end{array}$ & $\begin{array}{l}\text { Number of } \\
\text { specimens } \\
\text { with years }\end{array}$ \\
\hline Manis crassicaudata & Asia & Endangered & Terrestrial & $12(11)$ & $8(8)$ \\
\hline Manis culionensis & Asia & $\begin{array}{l}\text { Critically } \\
\text { Endangered }\end{array}$ & $\begin{array}{l}\text { Semi- } \\
\text { arboreal }\end{array}$ & $9(6)$ & $3(2)$ \\
\hline Manis javanica & Asia & $\begin{array}{l}\text { Critically } \\
\text { Endangered }\end{array}$ & $\begin{array}{l}\text { Semi - } \\
\text { arboreal }\end{array}$ & $48(37)$ & $30(28)$ \\
\hline Manis pentadactyla & Asia & $\begin{array}{l}\text { Critically } \\
\text { Endangered }\end{array}$ & Terrestrial & $68(30)$ & $21(18)$ \\
\hline Phataginus tetradactyla & Africa & Vulnerable & Arboreal & $17(13)$ & $8(8)$ \\
\hline Phataginus tricuspis & Africa & Endangered & $\begin{array}{l}\text { Semi- } \\
\text { arboreal }\end{array}$ & $97(49)$ & $25(22)$ \\
\hline Smutsia temminckii & Africa & Vulnerable & Terrestrial & $11(9)$ & $6(6)$ \\
\hline Smutsia gigantea & Africa & Endangered & Terrestrial & $7(7)$ & $5(5)$ \\
\hline
\end{tabular}




\section{Figure 1}

Schematic representation of overlaps for a hypothetical species.

Black points are the localities that specimens were collected from. These locality points are surrounded by a point-radius polygon (green) to represent possible error in georeferencing, the radius of which is equivalent to the error extent recorded during georeferencing. The area of habitat (AOH) polygon for the species is in blue. Overlaps for this scenario would be as follows: (1) four of the five specimen localities (including error extents) fall within the $\mathrm{AOH}$, so percentage locality overlap is $80 \%$; and (2) the percentage area overlap between the point-radius polygons and $\mathrm{AOH}$ polygon is (from left to right) $0 \%, 50 \%, 100 \%, 100 \%$, and $25 \%$, meaning that mean percentage area overlap is $55 \%$.

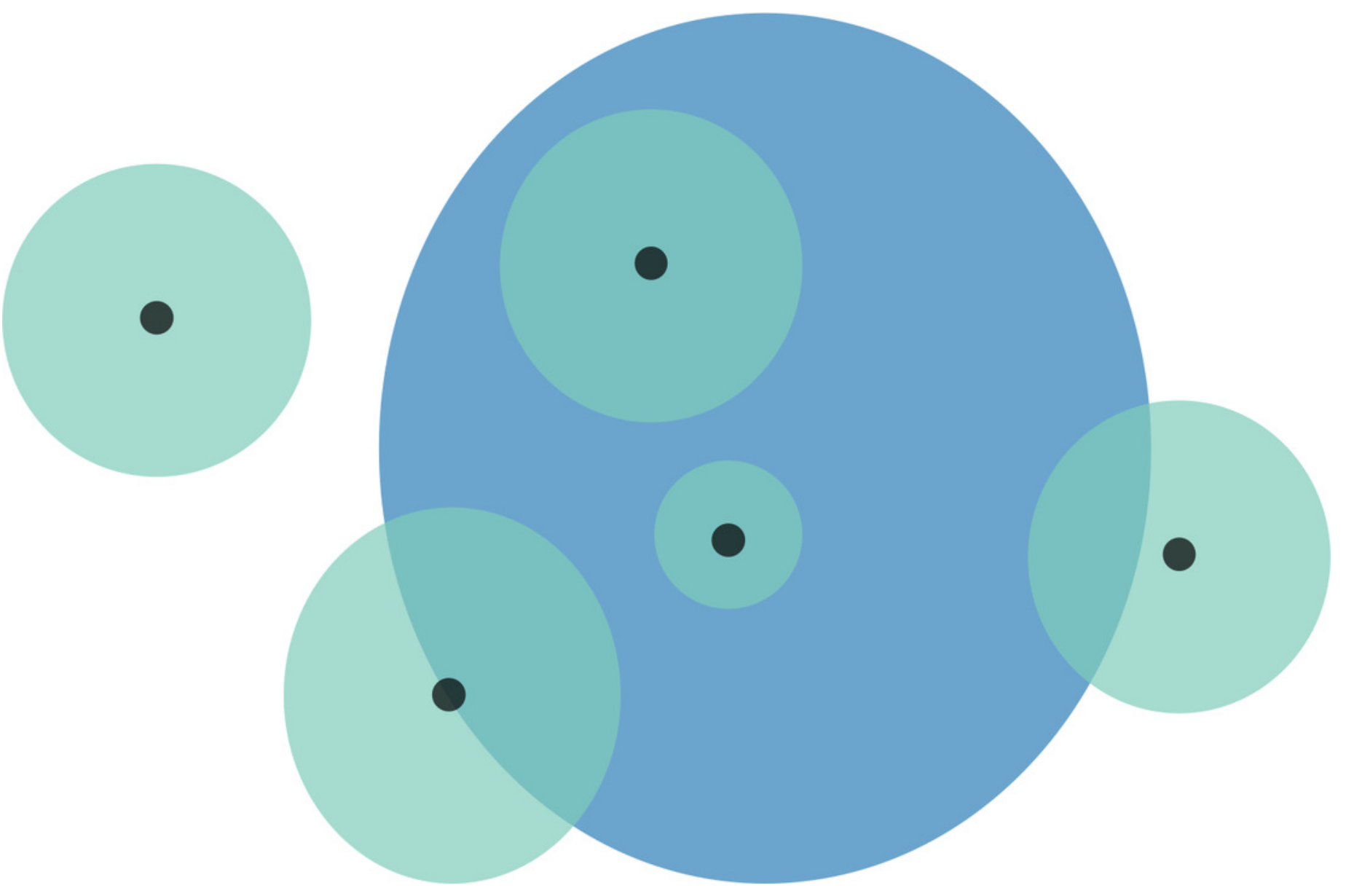


Figure 2

Distribution of Asian pangolins.

Point localities (black) with georeferencing error extents (green) and area of habitat maps (blue) for specimens of the four Asian pangolin species. Specimens with extents of greater than $1000 \mathrm{~km}$ were omitted for clarity. (A) Manis crassicaudata. (B) Manis culionensis. (C) Manis javanica. (D) Manis pentadactyla. 
A

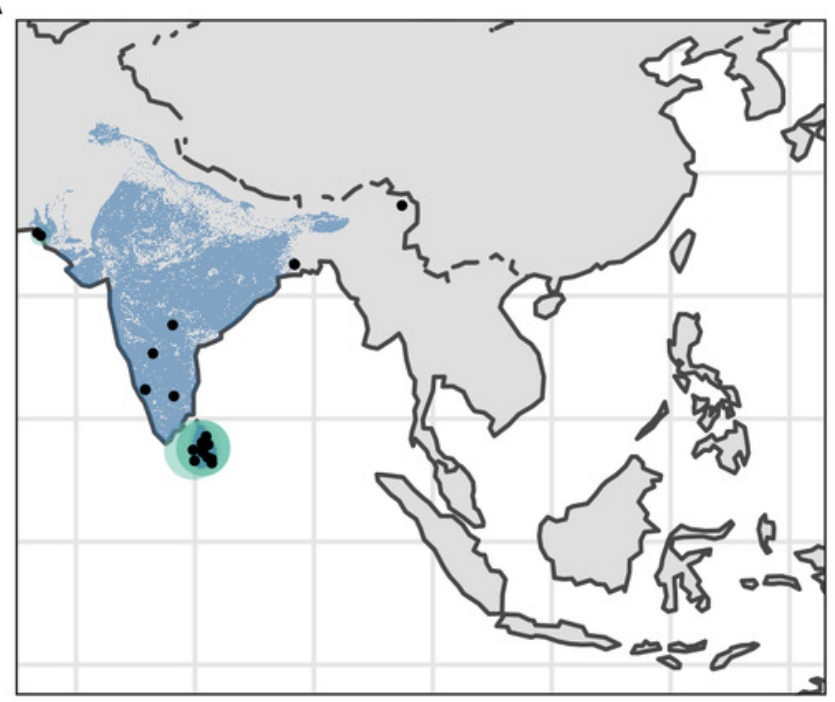

C

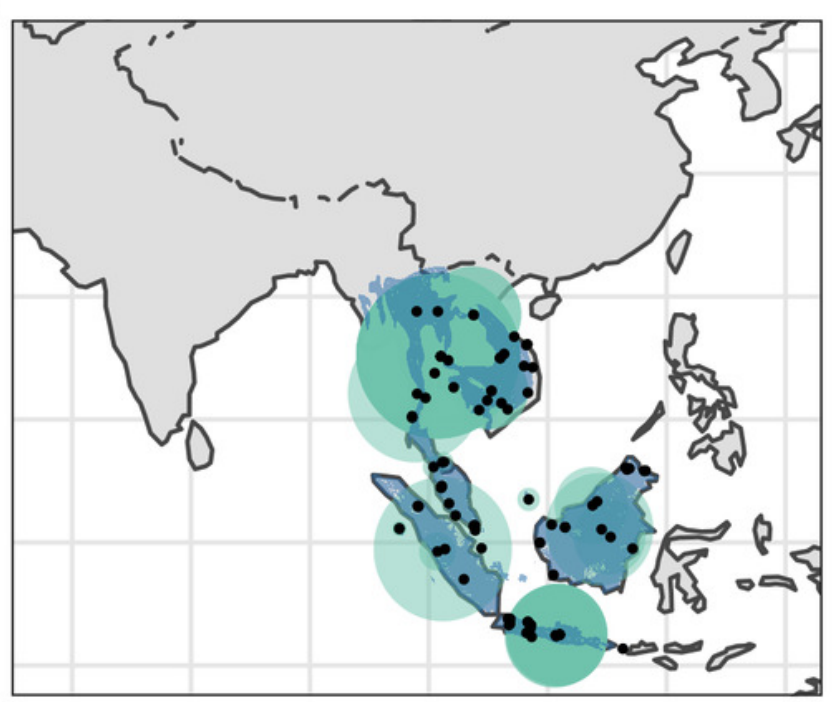

B

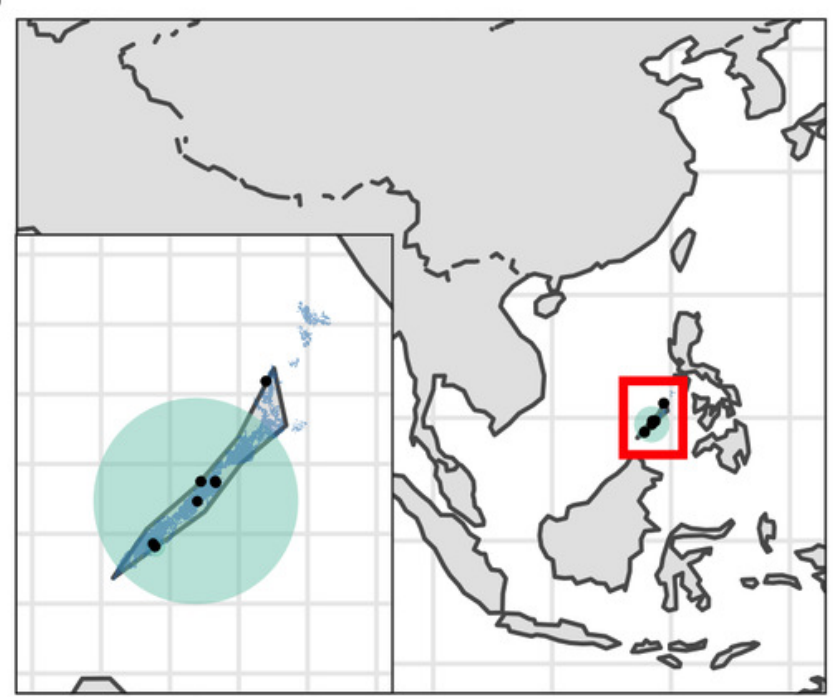

D

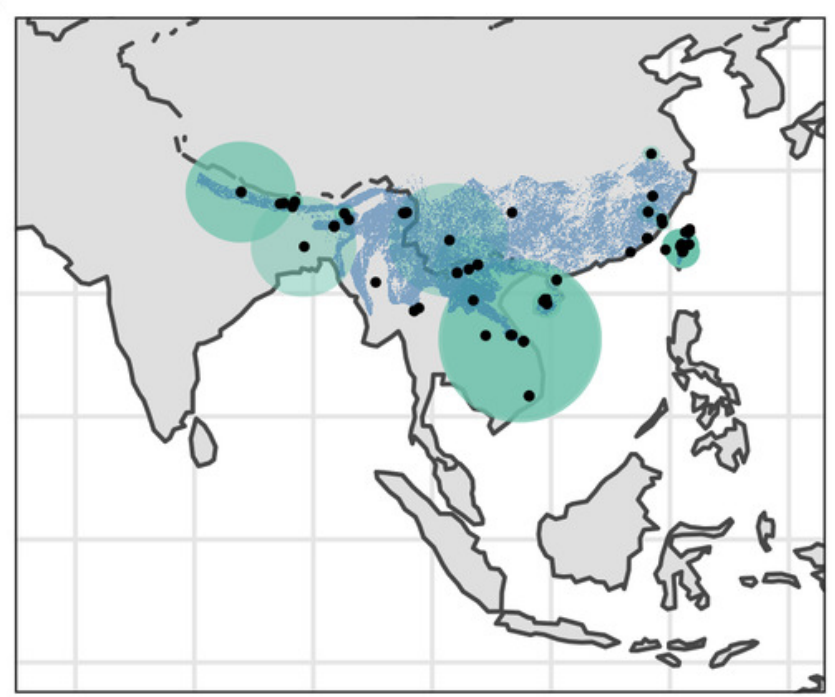




\section{Figure 3}

Distribution of African pangolins.

Point localities (black) with georeferencing error extents (green) and area of habitat maps (blue) for specimens of the four African pangolin species. Specimens with extents of greater than $1000 \mathrm{~km}$ were omitted for clarity. (A) Phataginus tetradactyla. (B) Phataginus tricuspis. (C) Smutsia gigantea. (D) Smutsia temminckii. 
A

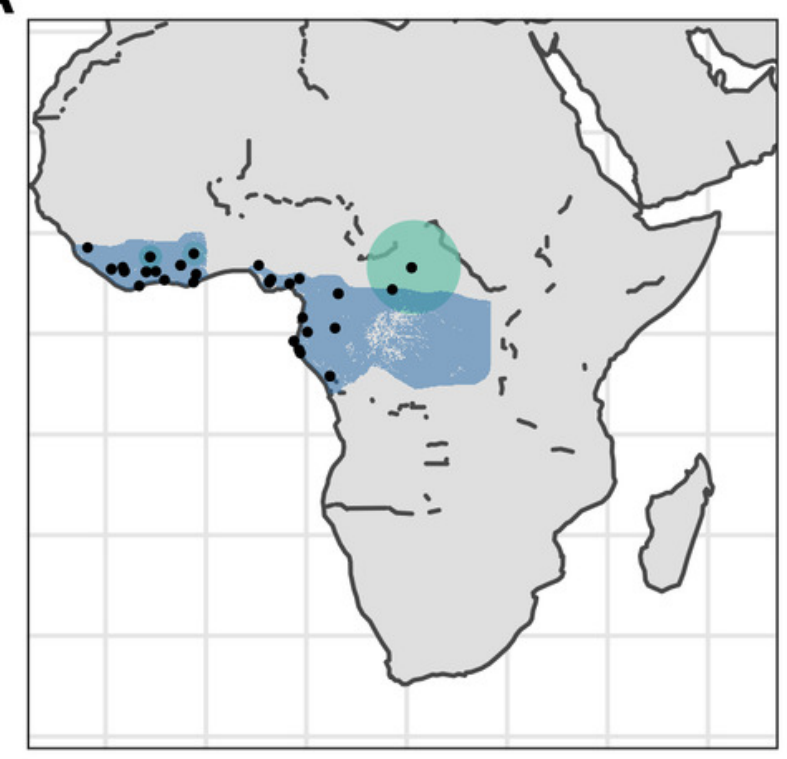

C

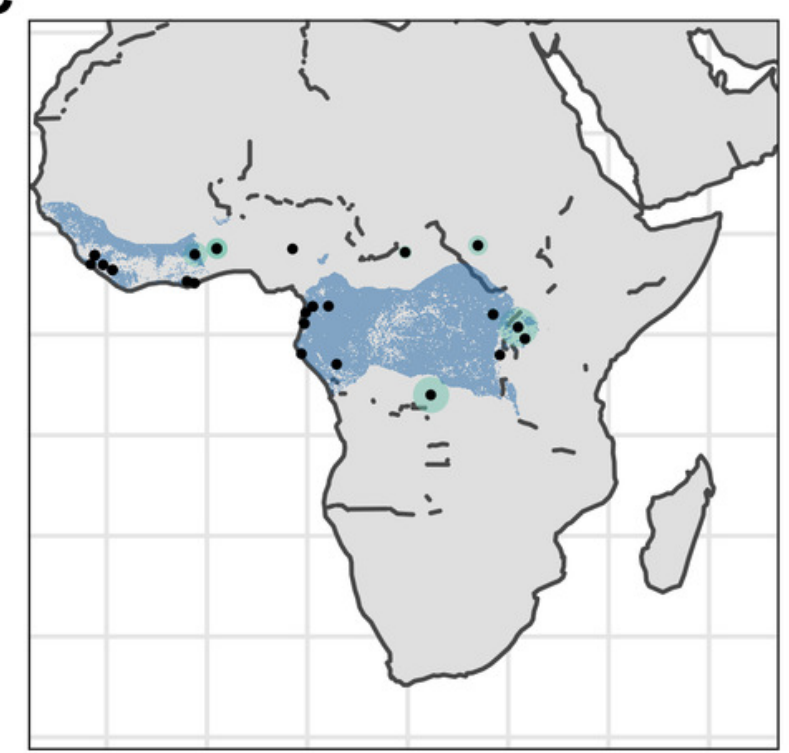

B

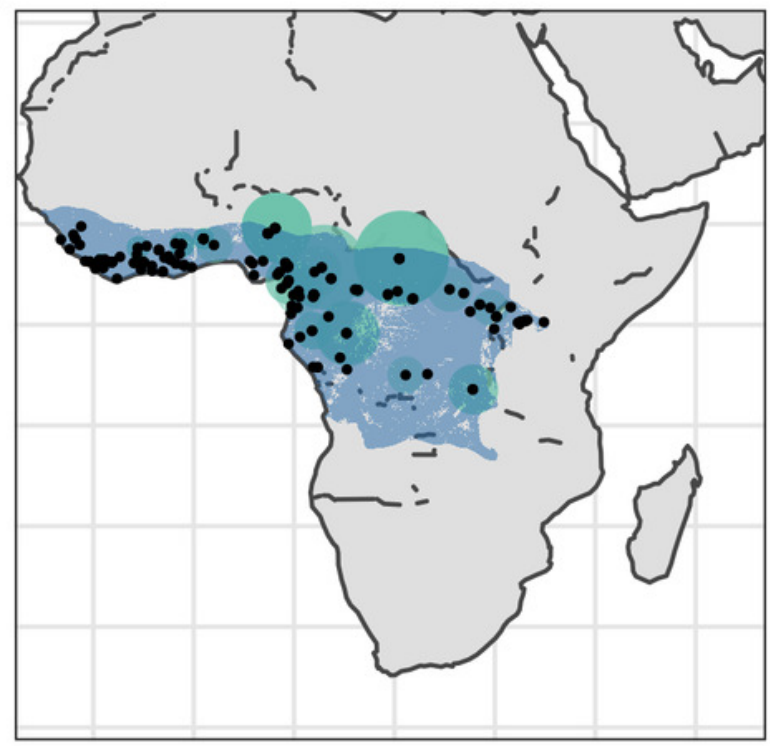

D

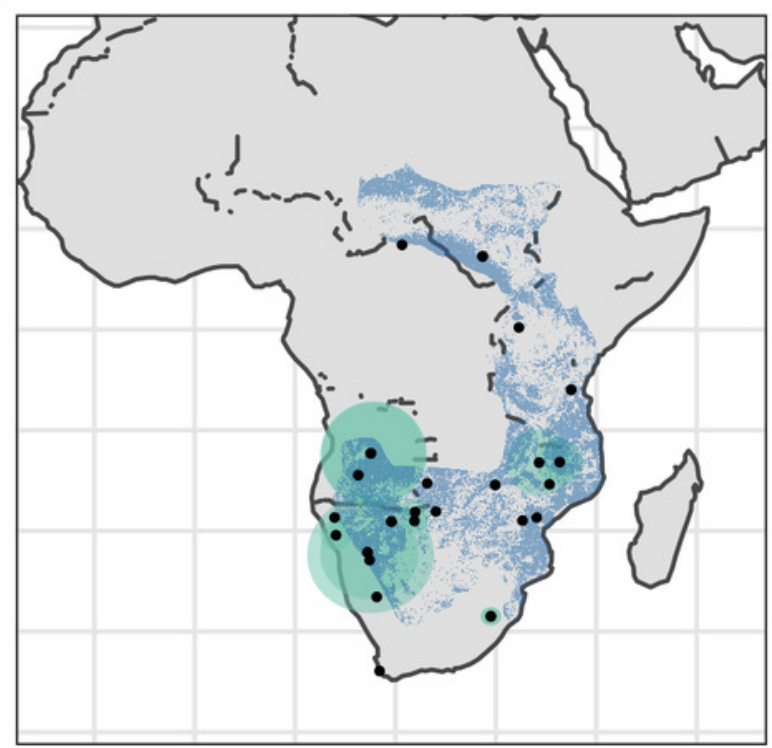


Figure 4

Correlates of percentage area overlaps.

Correlates of percentage area overlaps for each specimen, for specimens with certainty scores $\geq 50 \%$, extents $<50 \mathrm{~km}$ and excluding duplicates. (A) Species. (B) Collection year. (C) Continent. (D) Ecology. (E) IUCN Red List status. Black points are means, error bars show standard errors, grey points are the raw data. 
A
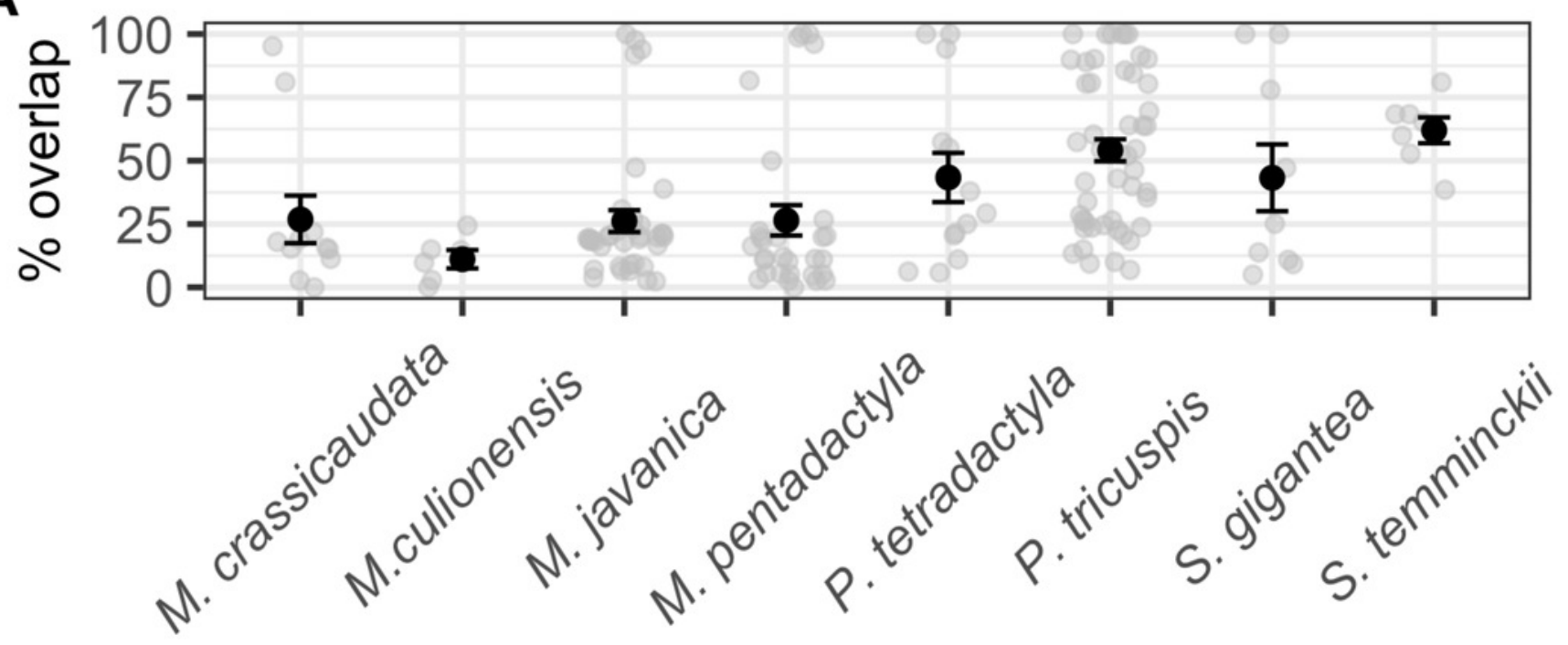

B

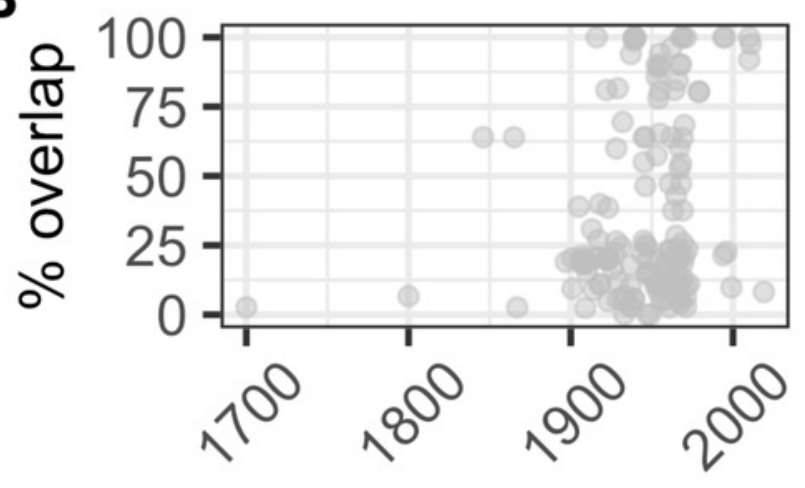

D

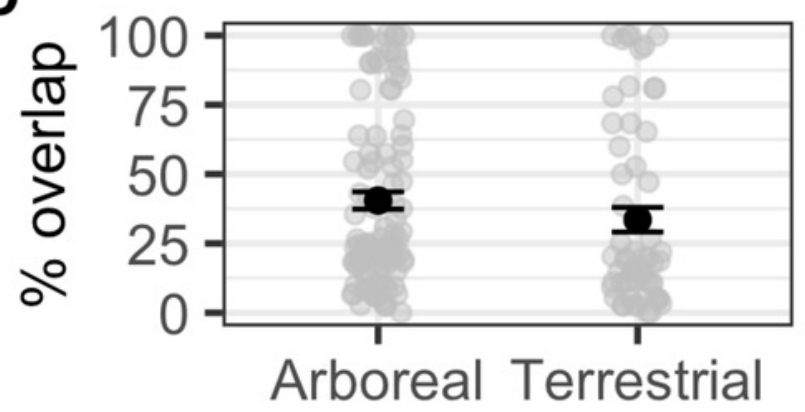

C

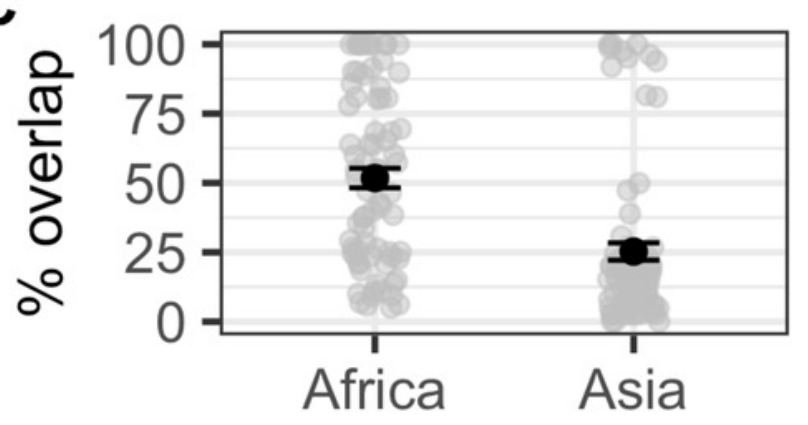

E

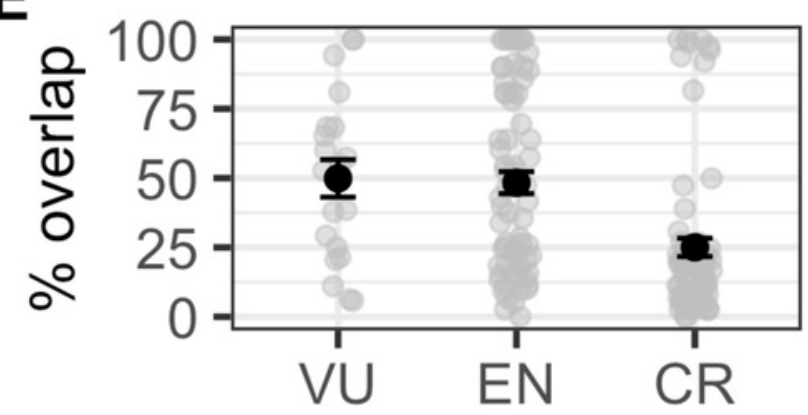


Figure 5

Percentage area overlap and population size.

Relationships between percentage area overlap and change in population count or population density within the point-radius polygon for each specimen between the present day and either 1850, 1900 or 1950 . (A) Population count 1850. (B) Population count 1900. (C) Population count 1950. (D) Population density 1850. (E) Population density 1900. (F) Population density 1950.

A

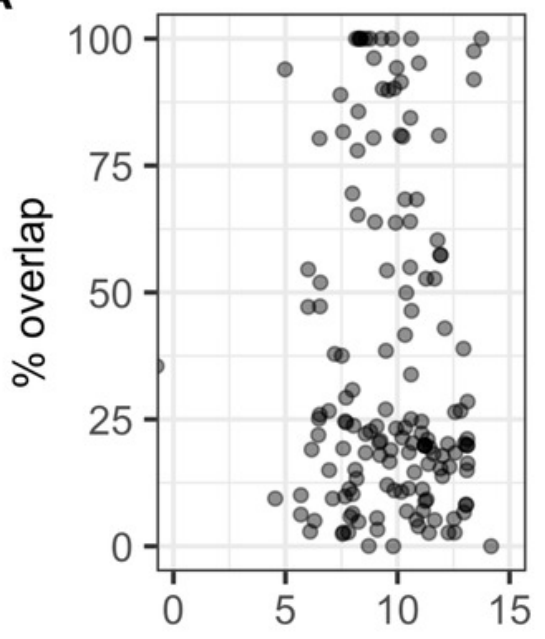

D

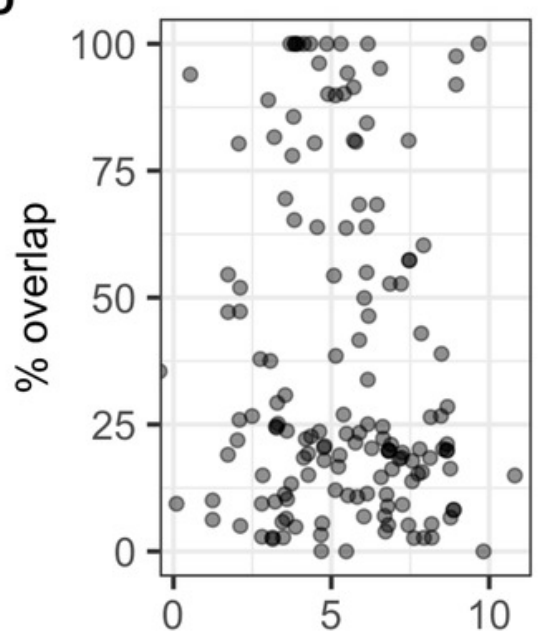

B

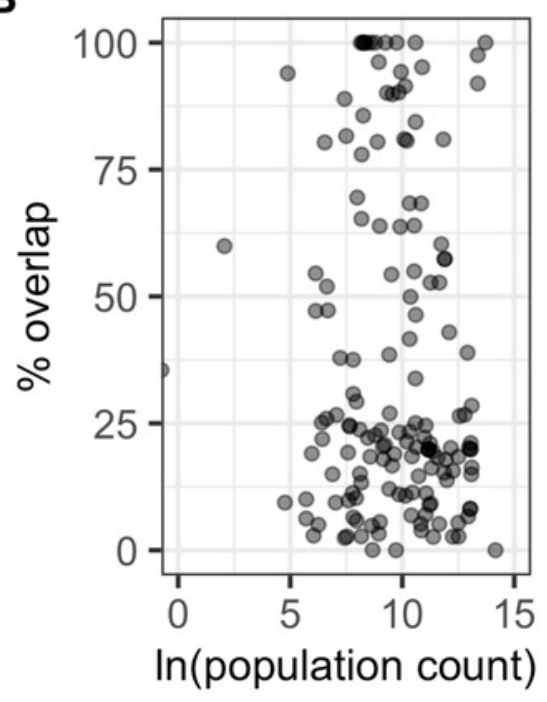

E

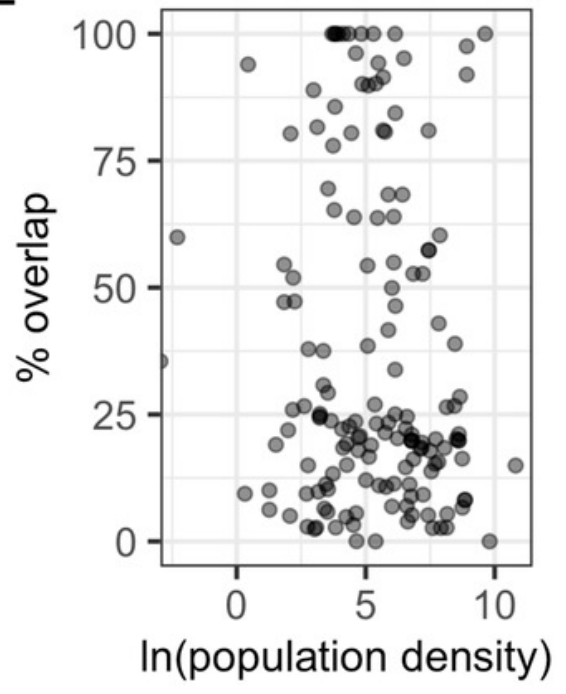

C

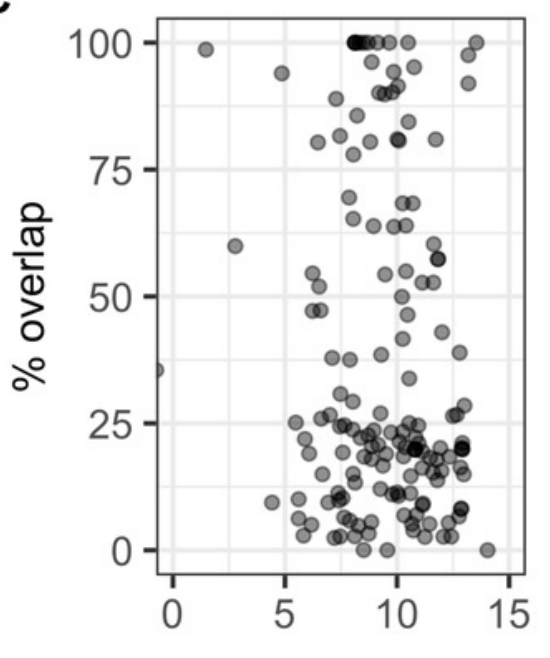

F

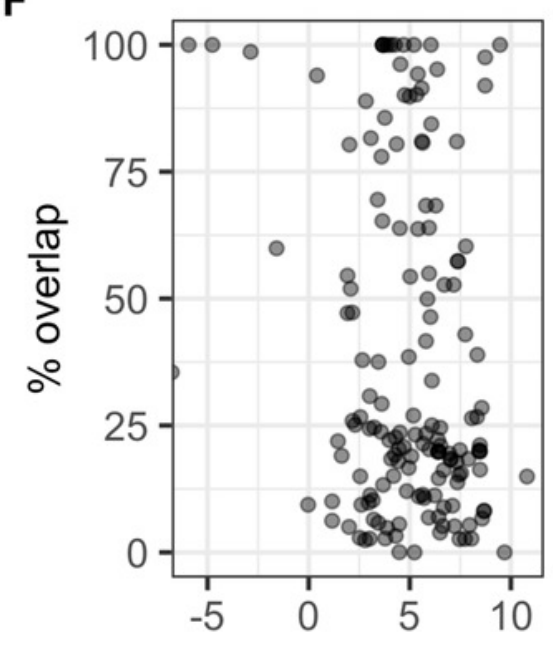




\section{Figure 6}

Percentage area overlap and land use change.

Relationships between percentage area overlap and change in primary forest cover, primary non-forest cover, and urban land cover within the point-radius polygon for each specimen between the present day and 1850, 1900 or 1950. Note that the $x$-axis is negative, showing a decrease in land cover, for primary forested and non-forested land, but positive, showing a decrease in land cover, for urban land. (A) Primary forest cover 1850. (B) Primary forest cover 1900. (C) Primary forest cover 1950. (D) Primary non-forest cover 1850. (E) Primary non-forest cover 1900. (F) Primary non-forest cover 1950. (G) Urban land cover 1850. (H) Urban land cover 1900. (I) Urban land cover 1950. 
A

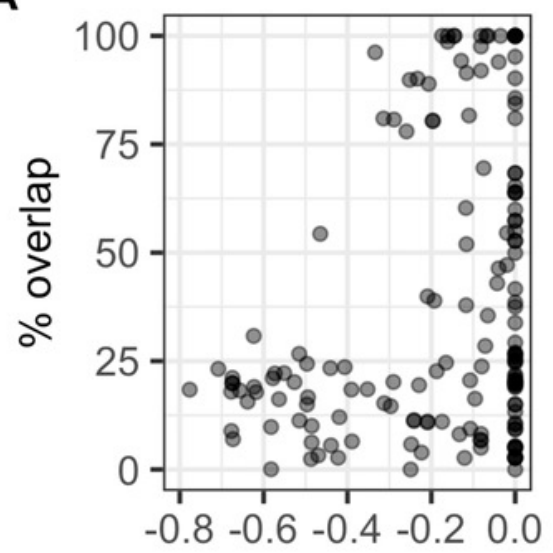

D

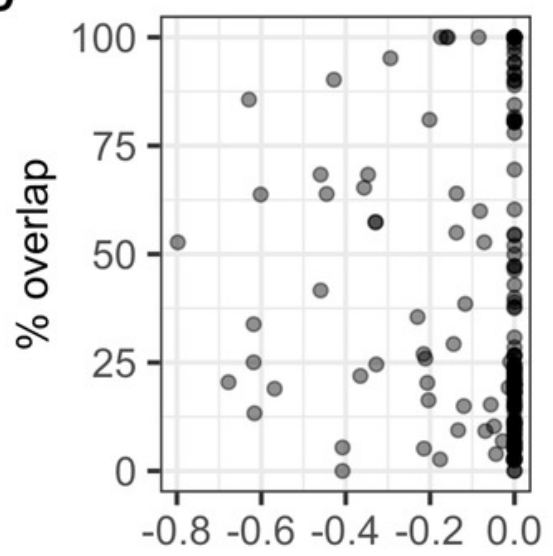

G

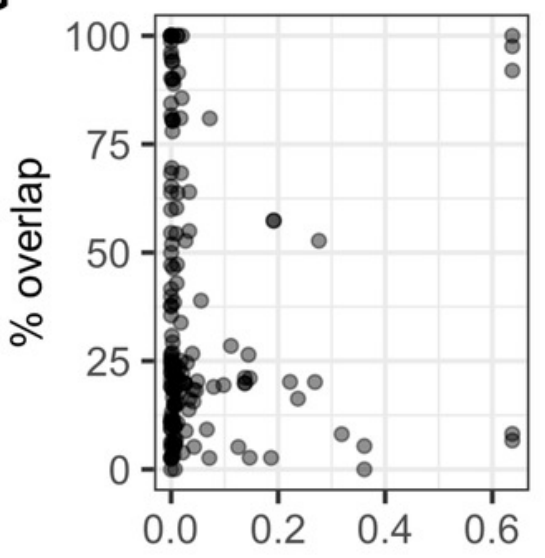

B

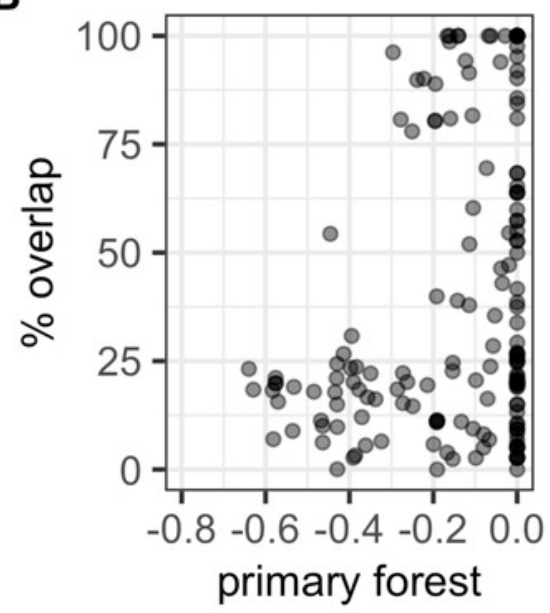

E

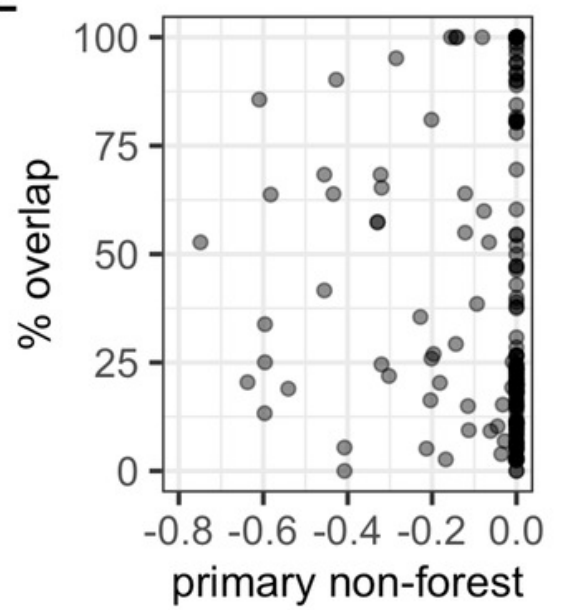

H

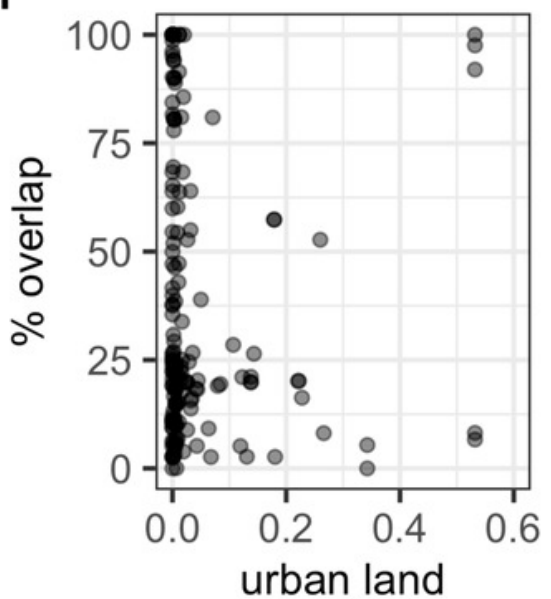

C

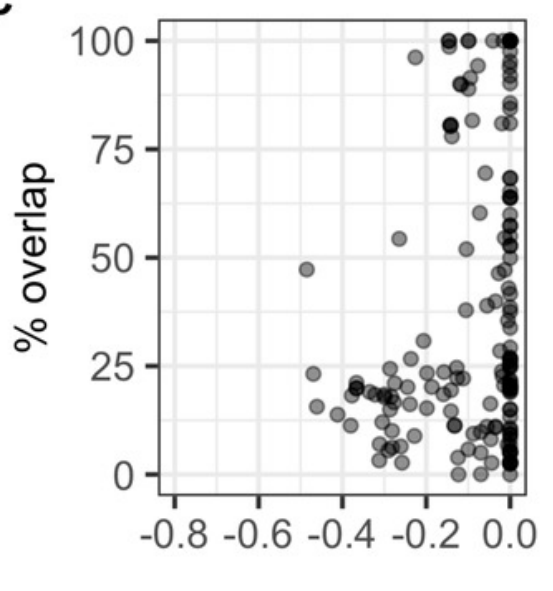

F

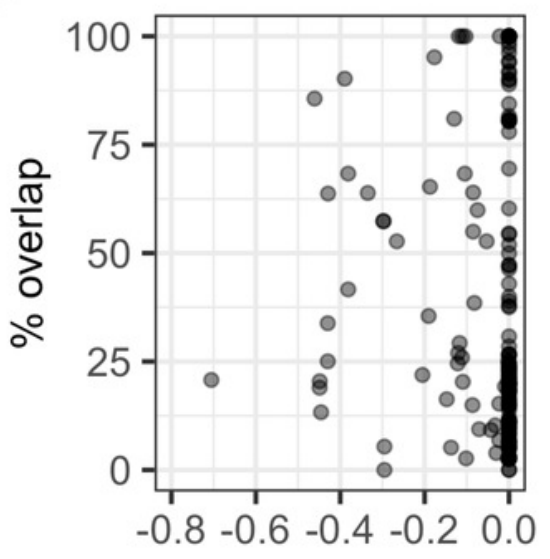

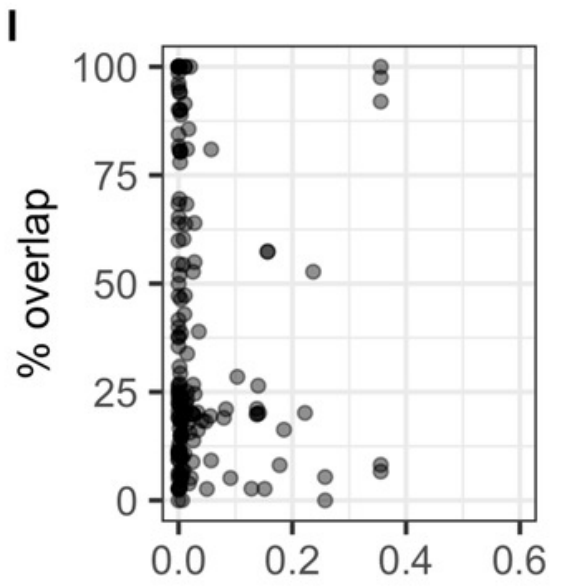

